Gazi University
Journal of Science
http://dergipark.gov.tr/gujs

\title{
Performance Analysis of Line-Start Concentrated Dual-winding Synchronous Reluctance Machine with Capacitive Assistance
}

\author{
Ayebatonye M. EPEMU ${ }^{1, *(D)}$, Donatus U. ONYISHI ${ }^{1}$ (D), Emeka S. OBE ${ }^{2}$ \\ ${ }^{I}$ Federal University of Petroleum Resources Effurun, Department of Electrical/Electronic Engineering, Effurun, Nigeria \\ ${ }^{2}$ University of Nigeria, Department of Electrical Engineering, Nsukka, Nigeria
}

Highlights

- This paper focuses on the modelling and analysis of the concentrated dual-winding SynRM.

- The use of the Direct-Phase Variable model and Winding Function Theory was used in the study.

- Improved performance characteristics were observed in the concentrated dual-winding SynRM.

\section{Article Info}

Received: 27 Feb 2021

Accepted: 05 Aug 2021

Keywords

Concentrated dual-winding Synchronous reluctance motor Direct-Phase variable model Winding function theory

\begin{abstract}
The transient and dynamic performance analysis of a proposed line-start, three-phase concentrated dual-winding synchronous reluctance motor (cDWSynRM) in comparison with the conventional concentrated winding synchronous reluctance motor (cSynRM) was presented. Both windings are overlapping windings. The cDWSynRM consist of main and auxiliary windings with capacitive assistance for power factor improvement. The modelling of the synchronous reluctance motors (SynRM) was done in direct-phase variables considering only the fundamental magneto-motive force (MMF). The machine inductances of both machine models were determined using winding function theory (WFT). These derived inductances were used to determine machine performance characteristics such as Torque, Speed, Phase currents etc. The performance characteristics of both motors were monitored using MATLAB/Simulink, and the proposed line-start cDWSynRM with capacitive assistance was observed to have improved performance characteristics when compared to the cSynRM.
\end{abstract}

\section{INTRODUCTION}

The synchronous reluctance motor (SynRM) is an AC machine that is singly salient, with a rotor constructed in a way that uses the principle of reluctance to produce electromechanical energy conversion. The SynRM is similar to the conventional salient pole synchronous motor, but has a stator like that of an induction machine (IM), and does not have an excitation winding on the rotor. To utilize the characteristic of the robust rotor, the motor is made to have a line-start operation with damper windings attached to the rotor of the machine [1]. The low cost of manufacturing, simple rugged structure, high-speed capability, lack of excitation losses, short-time overload capability etc., has made researchers see it as a viable alternative to other AC machines [2-5]. The major disadvantages of the SynRM are; its low output power, poor power factor and poor torque.

The stator windings of electrical machines can be classified as concentrated or distributed. Coils that have non-overlapping end windings were called concentrated windings, while distributed windings were made up of coils that have overlapping end windings. Concentrated windings could be grouped as overlapping and non-overlapping. The main advantages of adopting the concentrated winding machine topology are its compact design, having non-overlapping coil ends meaning lower copper loss, reduced axial length, and higher efficiency. Another benefit is its increased fill factor, which results in higher torque density/power density. This winding topology also gives a lower operating temperature and it is cheaper and easy to manufacture when compared to distributed windings [6-7]. 
An alternative to the use of permanent magnets and rotor geometry modification of the SynRM for its improvement is the splitting of the stator winding into two and reconnecting them with capacitors. Windings consisting of two separate parts, which can be connected in series and parallel are known as dual-windings. This concept was treated in [8-10], where two sets of windings are similar and share the available slot space in the stator of the machine. One set is supplied directly from the mains, while the other set is short-circuited through a balanced capacitor, which helps in improving the power factor of the motor. The two windings are isolated electrically but magnetically coupled like a conventional transformer. The output power of the SynRM is enhanced using dual stator windings and capacitance injection improves the power factor and torque of the machine. An experimental-based performance comparison of the dual winding SynRM was presented in [11]. A five-phase SynRM and Permanent Magnet SynRM was modelled and simulated in phase variables [12-13] and the results in phase variables tend to agree with that of the Finite Element Analysis.

The benefits of concentrated windings and dual-windings together have not been taken advantage of in the SynRM. Previous researches carried out on the SynRM considered the stator of the machine as having only concentrated, distributed, or having distributed dual stator winding [14-17]. Distributed windings were preferred over the concentrated were because the distributed winding gives a sinusoidal uniform MMF and analysis using the less complicated d-q model where consideration of only the fundamental component will be adequate.

Concentrated windings have been overlooked because it produces a significant amount of MMF harmonics, which may cause high iron loss. However, with appropriate slot and pole combinations, concentrated windings have the capability of producing sinusoidal MMF and EMF waveforms [18]. Recently, researchers have paid more attention to the interior permanent magnet machine (IPM) with concentrated windings but not the SynRM [19-22]. The purpose of this paper is to model the cDWSynRM and the cSynRM in direct-phase variables, compare their performance characteristics and show the viability of the models. It should be noted that the direct-phase model that considers only the fundamental MMF produces the same result as the $\mathrm{d}-\mathrm{q}$ model that involves complex transformations.

A 12-slot full-pitch cDWSynRM and a 12-slot full-pitch single layer cSynRM, with dimensions presented in Table 1 were used in this study. The winding clock diagrams are shown in Figure 1, and the traditional dumb-bell rotor with damper windings was used for this study. Figures 2 and 3 shows the machine connection diagrams of the cSynRM and the cDWSynRM respectively.

a)

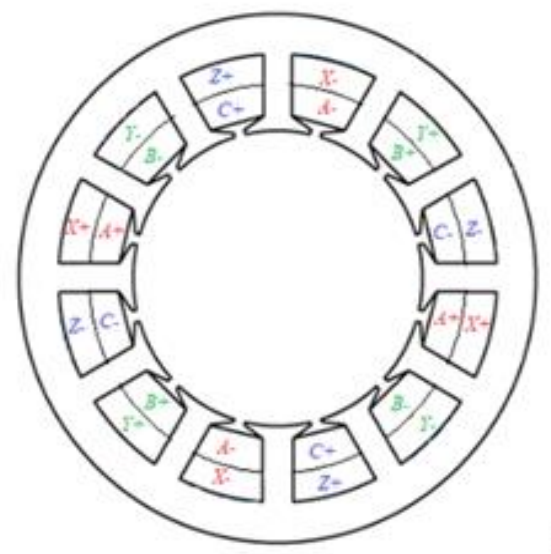

b)

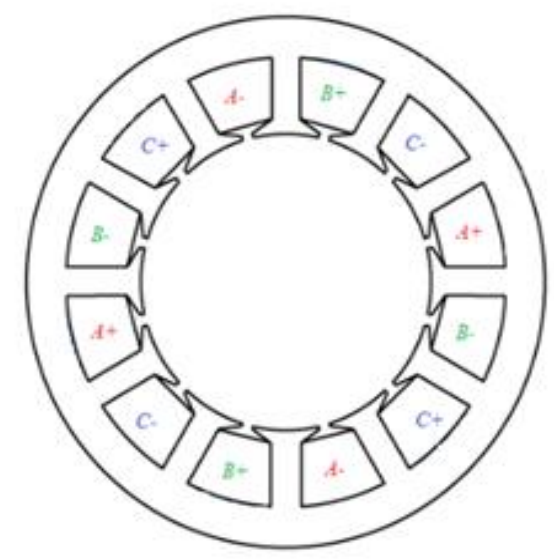

Figure 1. Winding Clock diagrams of (a) cDWSynRM, (b) $c$ SynRM 


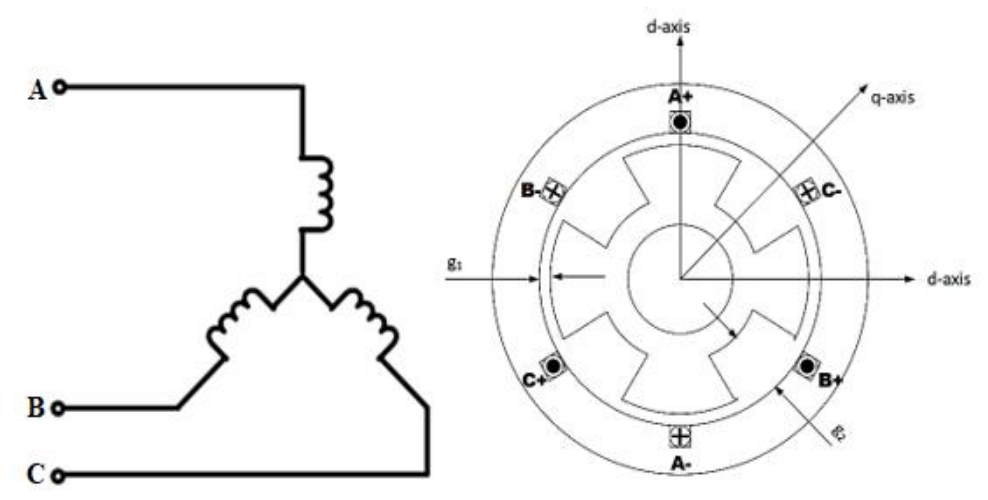

Figure 2. Machine connection diagram of a conventional concentrated stator winding reluctance motor

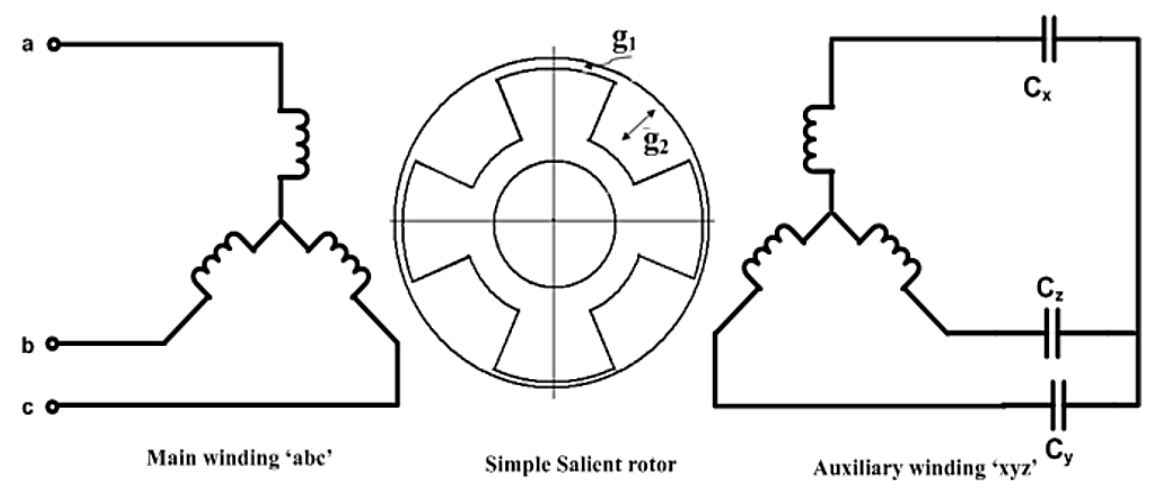

Figure 3. Machine connection diagram of a dual stator winding reluctance motor

Table 1. The machine dimensions

\begin{tabular}{|c|c|c|}
\hline Machine dimensions & \multicolumn{2}{|c|}{ Values } \\
\hline Stator outer radius & \multicolumn{2}{|c|}{$105.2 \mathrm{~mm}$} \\
\hline Stator inner radius & \multicolumn{2}{|c|}{$67.99 \mathrm{~mm}$} \\
\hline Rotor radius & \multicolumn{2}{|c|}{$67.69 \mathrm{~mm}$} \\
\hline Effective stack length & \multicolumn{2}{|c|}{160.22} \\
\hline Airgap length at pole face, $\mathrm{g}_{1}$ & \multicolumn{2}{|c|}{$0.4 \mathrm{~mm}$} \\
\hline Airgap length between poles, $\mathrm{g}_{2}$ & \multicolumn{2}{|c|}{$21.3 \mathrm{~mm}$} \\
\hline Stator slot depth & \multicolumn{2}{|c|}{$18 \mathrm{~mm}$} \\
\hline The ratio of pole arc to pole pitch & \multicolumn{2}{|c|}{$2 / 3$} \\
\hline Number of Pole pairs & \multicolumn{2}{|c|}{2} \\
\hline Winding connection & \multicolumn{2}{|c|}{$\mathrm{Y}$} \\
\hline & cDWSynRM & cSynRM \\
\hline Number of slots & 12 & 12 \\
\hline Number of turns & 48 & 36 \\
\hline Stator slot pitch & $30^{\circ}$ & 1 \\
\hline Number of Layers & 2 & \\
\hline
\end{tabular}

\section{METHODOLOGY}

The combination of winding function theory (WFT) and the direct-phase variable model was used in the study. The machine inductances were calculated using WFT and the results were used for the direct-phase variable simulation in MATLAB/Simulink. 


\subsection{Calculation of Machine Inductances}

The calculation of machine inductances of the cDWSynRM was carried out using WFT as used in [23-24]. The winding function of an arbitrary phase $\mathrm{A}$ for the main winding and arbitrary phase $\mathrm{X}$ for the auxiliary winding, with Pp number of pole-pairs by Fourier series, is presented in (1) and (2)

$$
\begin{aligned}
& N_{A}(\phi)=\sum_{n=1,3,5, \ldots}^{\infty} \frac{4 N_{t} k_{w n}}{P_{p} n \pi} \cos P_{p} n\left(\varphi-\kappa \frac{2 \pi}{m P_{p}}\right) \\
& N_{X}(\phi)=\sum_{n=1,3,5, \ldots .}^{\infty} \frac{4 N_{t} k_{w n}}{P_{p} n \pi} \cos P_{p} n\left(\varphi-\kappa \frac{2 \pi}{m P_{p}}\right)
\end{aligned}
$$

where, $k=0,1,2$, for stator winding phases $A, B, C$, respectively, and also for the auxiliary winding phases $X, Y, Z$ showing the phase shift of the various phases. $N_{t}$ is the number of turns per pole per phase, $P_{p}$ is the number of pole pairs, $n$ is the harmonic order, $m$ is the number of phases, $\varphi$ is the stator circumferential position and $k_{w n}$ is the winding factor for the $n$th harmonic.

The airgap expression is presented in (3) [24],

$g^{-1}\left(\phi, \theta_{r}\right)=\frac{1}{2}\left(\frac{1}{g_{1 c}}+\frac{1}{g_{2 c}}\right)-\frac{2}{n \pi}\left(\frac{1}{g_{1 c}}+\frac{1}{g_{2 c}}\right) \sin n \pi \beta \cos n\left(\phi-\theta_{r}\right)$

where $n$ is the number of harmonics, $g_{1 c}=k_{c s} \times k_{c r} \times g_{1}$ and $g_{2 c}=k_{c s} \times k_{c r} \times g_{2}$, with $k_{c s}$ and $k_{c r}$ represents Carter's coefficient for stator and rotor slot openings.

The $\mathrm{d}$-q components of the $\mathrm{d}$-axis and $\mathrm{q}$-axis rotor winding expression derived from [25], shown in Equations (4) and (5)

$N_{d r}\left(\varphi, \theta_{r}\right)=\frac{2}{\pi}\left[n_{m}+2 \sin ^{2} \frac{\gamma}{2}-\frac{\sin \left(n_{m} \gamma\right) \cos \left(n_{p} \gamma\right)}{\sin \gamma}\right] \sin \xi$
$N_{q r}\left(\varphi, \theta_{r}\right)=\frac{8}{\pi}\left[n_{m}-\frac{\cos \left(\frac{n_{b}-1}{2}\right) \sin \left(n_{m} \gamma\right)}{\sin \gamma}\right] \sin ^{2} \frac{\gamma}{2} \cos \xi$

where $n_{m}=1 / 2\left(n_{b}-2\right), n_{p}=1 / 2\left(n_{b}+2\right), n_{b}$ is the number of rotor bars per pole, $\gamma$ is an angle known as the rotor slot span and $\xi=\left(\varphi-\theta_{r}\right)$.

The actual rotor winding expression is presented in (6) and (7)

$$
\begin{aligned}
& N_{d r}(\phi)=\frac{4}{\pi} \sin ^{2}\left(\frac{\gamma}{2}\right)+\frac{4}{\pi} \sin ^{2}\left(\frac{3 \gamma}{2}\right)+\frac{4}{\pi} \sin ^{2}\left(\frac{5 \gamma}{2}\right) \\
& N_{q r}(\phi)=\frac{4}{\pi}\left[\cos \frac{\gamma}{2}-\cos \frac{3 \gamma}{2}\right]^{2}+\frac{4}{\pi}\left[\cos \frac{3 \gamma}{2}-\cos \frac{5 \gamma}{2}\right]^{2} .
\end{aligned}
$$

The expression for the calculation of stator self and mutual inductances is presented in (8) and (9)

$$
\begin{aligned}
& L_{A A}=\mu_{0} r l \int_{0}^{2 \pi} N_{A}^{2}(\phi) g^{-1}\left(\phi, \theta_{r}\right) d \phi \\
& L_{A B}=\mu_{0} r l \int_{0}^{2 \pi} n_{A}(\phi) N_{B}(\phi) g^{-1}\left(\phi, \theta_{r}\right) d \phi
\end{aligned}
$$

where $\mu_{0}$ is the magnetic permeability, $r$ is the machine radius, $l$ is the stack length. For the auxiliary winding, the self and mutual inductances are $L_{X X}$ and $L_{X Y}$. Inductance calculations using Equations (8) and (9) was achieved using trapezoidal numerical integration in MATLAB. In the calculation of these equations, the stator slots are held constant and the rotor is moved from 0 to $2 \pi$ radians. The inductance plots of the cDWSynRM are presented in Figures $4-7$. 


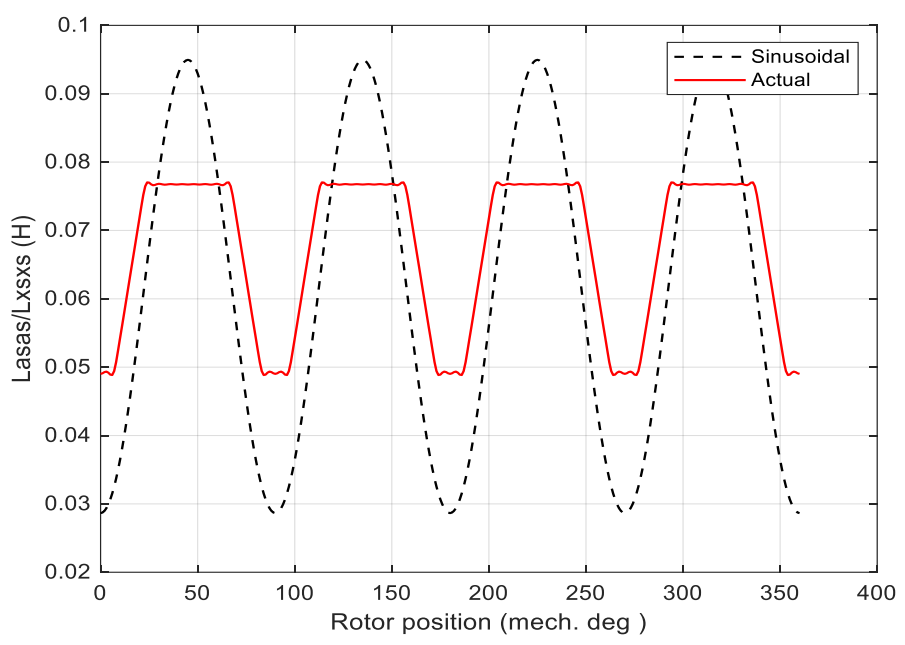

Figure 4. cDWSynRM Main/Auxiliary Stator Winding Self-inductance for phase A and phase X

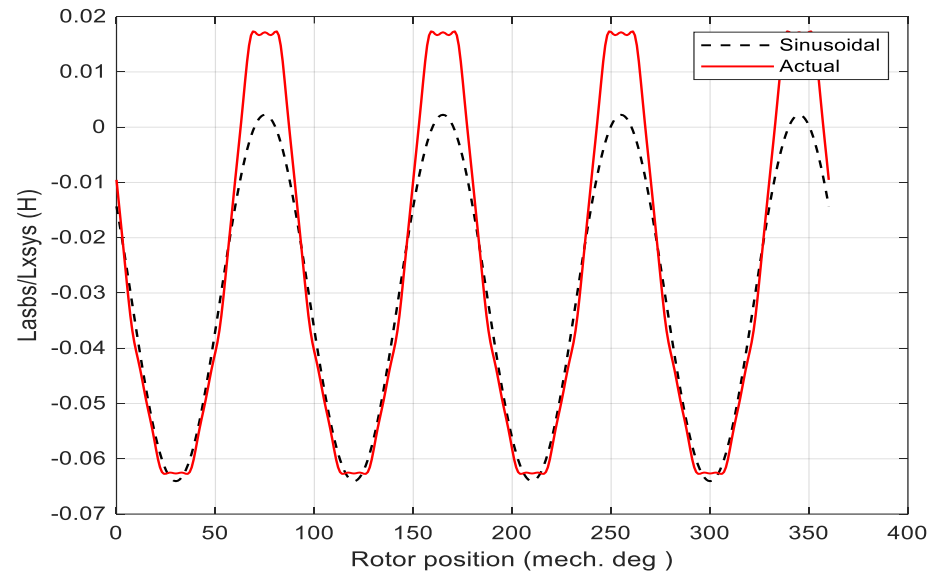

Figure 5. cDWSynRM Main/Auxiliary Stator Winding mutual-inductances for phases A\&B and phases $X \& Y$

Coupling inductance between the main and the auxiliary winding will be the same as seen in Figure 5 .

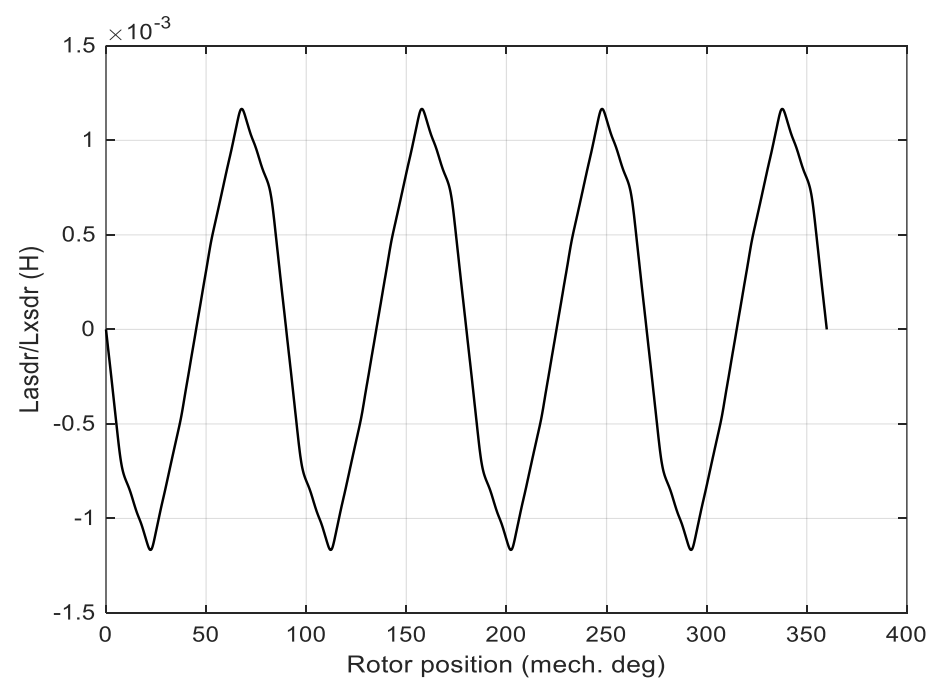

Figure 6. cDWSynRM actual mutual-inductance between concentrated main/auxiliary winding and daxis rotor winding 


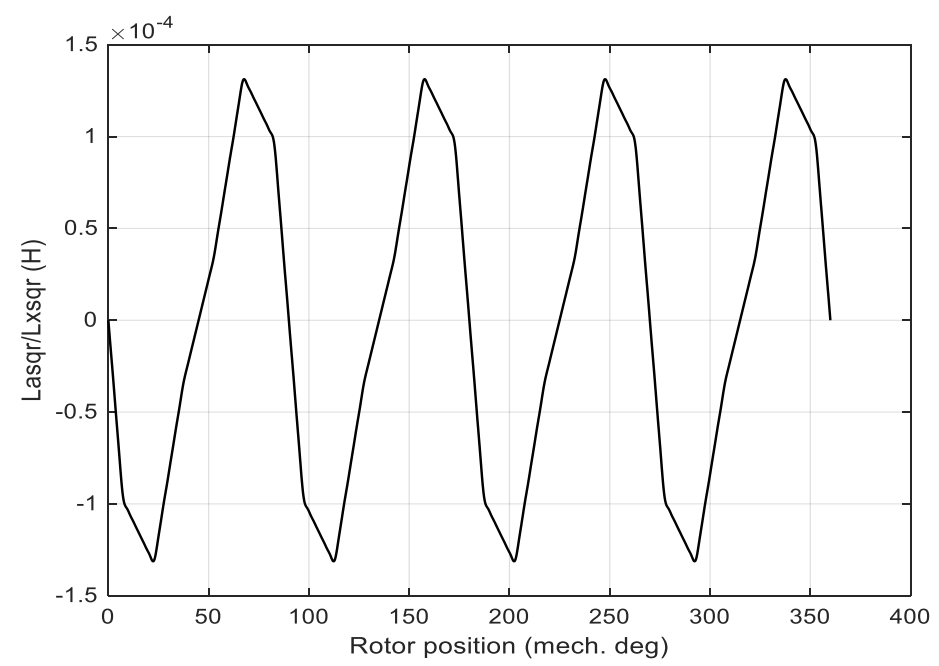

Figure 7. cDWSynRM actual mutual-inductance between concentrated main/auxiliary winding and qaxis rotor winding

\subsection{The Direct-Phase Variable Model of the cDWSynRM}

The voltage equations depict the electrical behaviour of the cDWSynRM and are expressed as follows;

$$
\begin{aligned}
& V_{a b c s}=R_{a b c s} i_{a b c s}+\frac{d}{d t} \lambda_{a b c s} \\
& V_{x y z s}=R_{x y z s} i_{x y z s}+\frac{d}{d t} \lambda_{x y z s}+V c_{x y z s} \\
& V_{q d r}=R_{q d r} i_{q d r}+\frac{d}{d t} \lambda_{q d r}
\end{aligned}
$$

Equations (10) and (11) are the voltage equations of the main and auxiliary winding respectively and Equation (12) is the rotor cage voltage equation, where the parameters of these equations in matrix form are

$$
\begin{aligned}
& V_{a b c s}^{T}=\left[\begin{array}{lll}
V_{a s} & V_{b s} & V_{c s}
\end{array}\right] \\
& V_{x y z s}^{T}=\left[\begin{array}{lll}
V_{x s} & V_{y s} & V_{z s}
\end{array}\right] \\
& V_{q d r}^{T}=\left[\begin{array}{ll}
V_{q r} & V_{d r}
\end{array}\right] \\
& R_{a b c s}=\operatorname{diag}\left[\begin{array}{lll}
R_{a s} & R_{b s} & R_{c s}
\end{array}\right] \\
& R_{x y z s}=\operatorname{diag}\left[\begin{array}{lll}
R_{x s} & R_{y s} & R_{z s}
\end{array}\right] \\
& R_{q d r}=\operatorname{diag}\left[R_{q r} \quad R_{d r}\right] \\
& i_{a b c s}^{T}=\left[\begin{array}{lll}
i_{a s} & i_{b s} & i_{c s}
\end{array}\right] \\
& i_{x y z s}^{T}=\left[\begin{array}{lll}
i_{x s} & i_{y s} & i_{z s}
\end{array}\right] \\
& i_{q d r}^{T}=\left[\begin{array}{ll}
i_{q r} & i_{d r}
\end{array}\right] \\
& \lambda_{a b c s}^{T}=\left[\begin{array}{lll}
\lambda_{a s} & \lambda_{b s} & \lambda_{c s}
\end{array}\right]
\end{aligned}
$$




$$
\begin{aligned}
& \lambda_{x y z s}^{T}=\left[\begin{array}{lll}
\lambda_{x s} & \lambda_{y s} & \lambda_{z s}
\end{array}\right] \\
& \lambda_{q d r}^{T}=\left[\begin{array}{ll}
\lambda_{q r} & \lambda_{d r}
\end{array}\right] \\
& V c_{x y z s}^{T}=\left[\begin{array}{lll}
V c_{x s} & V c_{y s} & V c_{z s}
\end{array}\right] .
\end{aligned}
$$

The currents on the auxiliary windings in (11) can be expressed in terms of capacitor voltage as

$$
i_{x y z s}=C \frac{d}{d t} V c_{x y z s} \text {. }
$$

The flux linkage equations of the main, auxiliary and rotor windings are expressed in Equations (27) - (29)

$\lambda_{a b c s}=L_{a b c s} i_{a b c s}+L_{a b c x y z s} i_{x y z s}+L_{a b c s q d r} i_{q d r}$

$\lambda_{x y z s}=L_{x y z s} i_{x y z s}+L_{x y z a b c s} i_{a b c s}+L_{x y z s q d r} i_{q d r}$

$\lambda_{q d r}=L_{q d r} i_{q d r}+L_{q d r a b c s} i_{a b c s}+L_{q d r x y z s} i_{x y z s}$.

The inductances $L_{a b c s}$ and $L_{x y z s}$ are the self and mutual inductances of the main and auxiliary winding respectively. The inductances $L_{a b c x y z s}, L_{x y z a b c s}$ are coupling inductances between the two stator windings and $L_{a b c s q d r}$ and $L_{x y z s q d r}$ are mutual inductances of the stator and the rotor cage windings.

Note that the subscript $s$ and $r$ symbolize the variables related to the stator and rotor windings.

The inductances are written in matrix form as follows;

$$
\begin{aligned}
& L_{a b c s}=\left[\begin{array}{lll}
L_{a s a s} & L_{a s b s} & L_{a s c s} \\
L_{b s a s} & L_{b s b s} & L_{b s c s} \\
L_{c s a s} & L_{c s b s} & L_{c s c}
\end{array}\right] \\
& L_{x y z s}=\left[\begin{array}{lll}
L_{x s x s} & L_{x s y s} & L_{x s z s} \\
L_{y s x s} & L_{y s y s} & L_{y s z s} \\
L_{z s x s} & L_{z s y s} & L_{z s z s}
\end{array}\right] \\
& L_{a b c x y z s}=L_{x y z a b c s}^{T}\left[\begin{array}{lll}
L_{a s x s} & L_{a s y s} & L_{a s z s} \\
L_{c s x s} & L_{b s y s} & L_{b s z s} \\
L_{c s z s}
\end{array}\right] \\
& L_{a b c s q d r}=\left[\begin{array}{ll}
L_{a s q r} & L_{a s d r} \\
L_{b s q r} & L_{b s d r} \\
L_{c s q r} & L_{c s d r}
\end{array}\right] \\
& L_{x y z s q d r}=\left[\begin{array}{ll}
L_{x s q r} & L_{x s d r} \\
L_{y s q r} & L_{y s d r} \\
L_{z s q r} & L_{z s d r}
\end{array}\right] \\
& L_{q d r}=\left[\begin{array}{ll}
L_{q r} & L_{q d r} \\
L_{d q r} & L_{d r}
\end{array}\right] .
\end{aligned}
$$

Note that the diagonal components in Equations (30) - (35) contains the magnetizing and the leakage components.

The main stator winding self and mutual inductances, including all winding harmonics could be expressed as shown in Equations (36) and (37) 


$$
\begin{aligned}
& L_{a s a s}=L_{l a}+L_{a a 0}-\sum_{k=2,4,6, \ldots}^{\infty} c_{s k} L_{a a 1} \cos \left(2 p_{p} k \theta_{r}-\alpha_{s k}\right) \\
& L_{a s b s}=-\frac{1}{2} L_{a a o}-\sum_{k=2,4,6, \ldots}^{\infty} c_{m k} L_{a a 1} \cos \left(2 p_{p} k \theta_{r}-\alpha_{m k}\right) .
\end{aligned}
$$

The auxiliary stator winding self and mutual inductances $L_{x s x s}, L_{x s y s}$, coupling inductances between the main and the auxiliary winding $L_{a s x s}, L_{a s y s}$ including all winding harmonics are similar to Equations (36) and (37). The main and auxiliary stator leakage inductances are denoted as $L_{l a}$ and $L_{l x}$.

The mutual inductances between the two stator windings and the rotor cage winding in the q-axis and daxis, including all winding harmonics are stated as

$$
\begin{aligned}
& L_{a s q r}=\sum_{k=1,3,5, \ldots}^{\infty} c_{q k} L_{m q 1} \cos \left(p_{p} k \theta_{r}-\alpha_{q k}\right) \\
& L_{a s d r}=\sum_{k=1,3,5, \ldots . .}^{\infty} c_{d k} L_{m d 1} \sin \left(p_{p} k \theta_{r}-\alpha_{d k}\right) \\
& L_{x s q r}=\sum_{k=1,3,5, \ldots .}^{\infty} c_{q k} L_{m q 2} \cos \left(p_{p} k \theta_{r}-\alpha_{q k}\right) \\
& L_{x s d r}=\sum_{k=1,3,5, \ldots}^{\infty} c_{d k} L_{m d 2} \sin \left(p_{p} k \theta_{r}-\alpha_{d k}\right)
\end{aligned}
$$

where

$$
\left\{\begin{array}{l}
L_{m q 1}=\frac{3}{2}\left(L_{a a 0}-L_{a a 1}\right) \\
L_{m d 1}=\frac{3}{2}\left(L_{a a 0}+L_{a a 1}\right) \\
L_{m q 2}=\frac{3}{2}\left(L_{x x 0}-L_{x x 1}\right) \\
L_{m d 2}=\frac{3}{2}\left(L_{x x 0}+L_{x x 1}\right)
\end{array} .\right.
$$

Note that the values of $L_{a a 0}, L_{a a 1}, L_{x x 0}, L_{x x 1}, L_{a x 0}$ and $L_{a x 1}$ are values from the inductance plots shown in section 2.1. Where the angle $\alpha$ is the four-quadrant arctangent representing the angular displacement of each harmonic from the reference, gotten from each harmonic of the inductances using Fourier series procedure with MATLAB function atan2. The constants $c_{s k}, c_{m k}, c_{q k}$ and $c_{d k}$ are amplitudes derived from inductance plots of $L_{a s a s}, L_{a s b s}, L_{a s d r}$ and $L_{a s q r}$ given in the methodology.

Referring rotor variables to stator windings, flux linkage can be presented in (43)

$$
\left[\begin{array}{c}
\lambda_{a b c s} \\
\lambda_{x y z s} \\
\lambda^{\prime}{ }_{q d r}
\end{array}\right]=\left[\begin{array}{ccc}
L_{a b c s} & L_{a b c x y z s} & L_{\text {abcsqdr }}^{\prime} \\
L_{\text {abcxyzs }}^{T} & L_{x y z s} & L_{x y z s q d r}^{\prime} \\
\frac{2}{3}\left(L^{\prime}{ }_{\text {abcsqdr }}\right)^{T} & \frac{2}{3}\left(L_{\text {xyzsqdr }}^{\prime}\right)^{T} & L_{\text {qdr }}^{\prime}
\end{array}\right]\left[\begin{array}{c}
i_{a b c s} \\
i_{x y z s} \\
i_{q d r}^{\prime}
\end{array}\right] .
$$

Therefore, inductance referred to the rotor parameter is given as

$$
L\left(\theta_{r}\right)=\left[\begin{array}{ccc}
L_{a b c s} & L_{\text {abcxyzs }} & L_{\text {abcsqdr }}^{\prime} \\
L_{\text {abcxyzs }}^{T} & L_{x y z s} & L_{x y z s q d r}^{\prime} \\
\frac{2}{3}\left(L_{\text {abcsqdr }}^{\prime}\right)^{T} & \frac{2}{3}\left(L_{\text {xyzsqdr }}^{\prime}\right)^{T} & L_{\text {qdr }}^{\prime}
\end{array}\right] .
$$

The stator inductances alone are expressed in Equation (45),

$$
L_{s s}=\left[\begin{array}{cc}
L_{a b c s} & L_{a b c x y z s} \\
L_{a b c x y z s}^{T} & L_{x y z s}
\end{array}\right]
$$

Referring the self-inductances of the rotor cage windings to the stator, 
$L_{q d r}^{\prime}=\left[\begin{array}{cc}L_{l q r}^{\prime}+L_{m q} & 0 \\ 0 & L_{l d r}^{\prime}+L_{m d}\end{array}\right]$

The electromagnetic torque equation of the cDWSynRM derived from co-energy is presented in (47)

$T_{e m}=\frac{p}{2} I_{S}^{T} \frac{\partial\left[L_{S}\right]}{\partial \theta_{r}} I_{S}$

where

$L_{s}=\left[\begin{array}{ccc}L_{a b c s} & L_{\text {abcxyzs }} & L_{\text {abcsqdr }} \\ L_{a b c x y z s}^{T} & L_{x y z s} & L_{x y z s q d r} \\ L_{a b c s q d r}^{T} & L_{x y z q d r}^{T} & L_{q d r}\end{array}\right]$

$I_{s}=\left[\begin{array}{lll}i_{a b c s} & i_{x y z s} & i_{q d r}\end{array}\right]^{T}$.

Substituting (48) and (49) into (47) gives the electromagnetic torque equation in (50) as the separate sum of torque produced by each stator current, showing the contribution of each winding

$T_{e m}=\frac{p}{2}\left\{\begin{array}{l}i_{a b c s}^{T} \frac{\partial L_{a b c s}}{\partial \theta_{r}} i_{a b c s}+i_{a b c s}^{T} \frac{\partial L_{a b c x y z s}}{\partial \theta_{r}} i_{x y z s}+i_{a b c s}^{T} \frac{\partial L_{a b c s q d r}}{\partial \theta_{r}} i_{q d r} \\ +i_{x y z s}^{T} \frac{\partial L_{x y z s}}{\partial \theta_{r}} i_{x y z s}+i_{x y z s}^{T} \frac{\partial L_{x y z a b c s}}{\partial \theta_{r}} i_{a b c s}+i_{x y z s}^{T} \frac{\partial L_{x y z s q d r}}{\partial \theta_{r}} i_{q d r} \\ +i_{q d r}^{T} \frac{\partial L_{a b c s q d r}^{T}}{\partial \theta_{r}} i_{a b c s}+i_{q d r}^{T} \frac{\partial L_{x y z q d r}^{T}}{\partial \theta_{r}} i_{x y z s}+i_{q d r}^{T} \frac{\partial L_{q d r}}{\partial \theta_{r}} i_{q d r}\end{array}\right\}$.

The relationship between the electromagnetic torque of the machine $T_{e m}$ and rotor speed $\omega_{r}$ is given in the mechanical dynamic equation while ignoring the effect of friction

$T_{e m}=J\left(\frac{2}{P}\right) p_{p} \omega_{r}+T_{L}$

where $J$ is the total inertia of the rotating mass, $T_{L}$ is the load torque, and $p_{p}$ is the number of rotor pole pairs.

\section{THE SIMULATION RESULTS AND DISCUSSION}

The dynamic simulation of the cDWSynRM and the cSynRM was carried out in direct-phase variables considering only their fundamentals using MATLAB/Simulink. The machine circuit parameters are presented in Table 2 was extrapolated from a similar conventional machine as presented in [1]. The cDWSynRM dimensions and parameters were determined using a similar procedure for splitting a stator as presented in [26]. Note that the values of the cDWSynRM in Table 2 is for one stator only.

The simulations were carried out at a constant supply voltage of $370 \mathrm{~V}$ for the cSynRM and $185 \mathrm{~V}$ for the cDWSynRM, which is half the voltage of the cSynRM and at a frequency of $50 \mathrm{~Hz}$. The inductances calculated in section 2.1 were also used for the simulation. The capacitor value of $73 \mu \mathrm{F}$ was selected for the cDWSynRM using a similar procedure as presented in [9]. The starting transients were observed in both machine models.

A load torque of $25 \mathrm{Nm}$ ( $70 \%$ of rated torque) was introduced at 1 second to observe the dynamic performance of both models. The results show small departures from synchronism, which get damped at a short period, due to the damper windings on the rotor. Figures $8-20$ show the performance characteristics of the cDWSynRM and the cSynRM. The simulation time of 2 seconds was used and a load torque of 25 $\mathrm{Nm}$ was introduced after 1 second. 
Table 2. The machine circuit parameters of the cSynRM and the cDWSynRM

\begin{tabular}{|l|l|l|}
\hline Parameter & \multicolumn{2}{|c|}{ Value } \\
\hline Frequency, $\mathrm{F}$ & $50 \mathrm{~Hz}$ \\
\hline Moment of inertia, $\mathrm{J}$ & $0.089 \mathrm{~kg} / \mathrm{m}^{2}$ \\
\hline Winding connection & $\mathrm{Y}$ \\
\hline Rated power, $\mathrm{P}_{\text {rated }}$ & $5.5 \mathrm{~kW}$ \\
\hline Number of pole pairs & 2 \\
\hline Rated Speed & $1500 \mathrm{rpm}$ \\
\hline Rated Torque, $\mathrm{T}_{\text {rated }}$ & $35 \mathrm{Nm}$ \\
\hline & $\mathrm{cSynRM}$ & $\mathrm{cDWSynRM}$ \\
\hline Phase Voltage, $\mathrm{V}_{\mathrm{ph}}$ & $370 \mathrm{~V}$ & $185 \mathrm{~V}$ \\
\hline Stator resistance, $\mathrm{R}_{\mathrm{s}}$ & $1.348 \Omega$ & $0.674 \Omega$ \\
\hline Stator leakage inductance, $\mathrm{L}_{\mathrm{ls}}$ & $1.609 \mathrm{mH}$ & $0.402 \mathrm{mH}$ \\
\hline Rotor d-axis leakage inductance, $\mathrm{L}_{\mathrm{ldr}}$ & $5.5 \mathrm{mH}$ & $1.38 \mathrm{mH}$ \\
\hline Rotor q-axis leakage inductance, $\mathrm{L}_{\mathrm{lq}}$ & $6.2 \mathrm{mH}$ & $1.55 \mathrm{mH}$ \\
\hline Rotor d-axis resistance, $\mathrm{R}_{\mathrm{dr}}$ & $0.12 \Omega$ & $0.03 \Omega$ \\
\hline Rotor q-axis resistance, $\mathrm{R}_{\mathrm{qr}}$ & $0.25 \Omega$ & $0.06 \Omega$ \\
\hline
\end{tabular}

\section{Simulation Results}

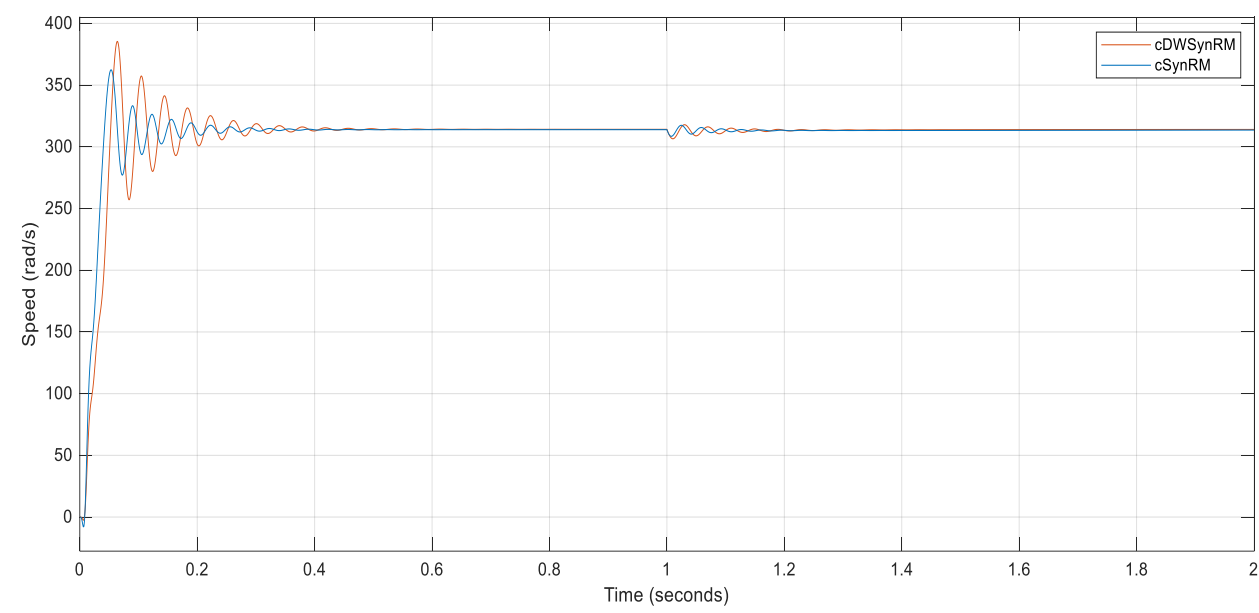

Figure 8. cDWSynRM and cSynRM speed against time

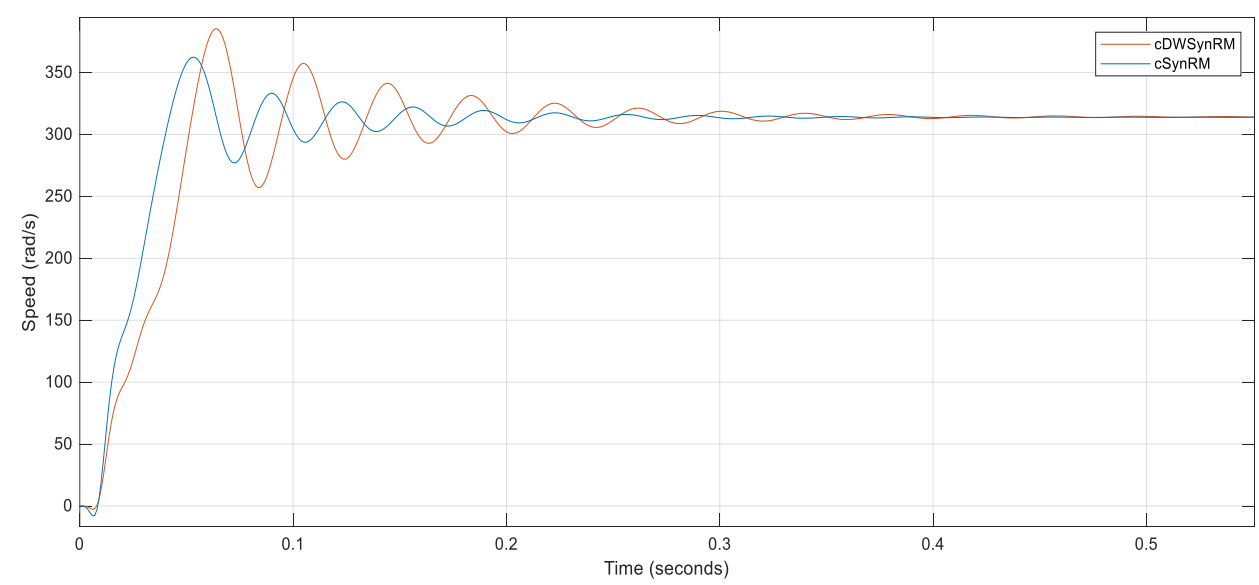

Figure 9. cDWSynRM and cSynRM speed transient at start-up 


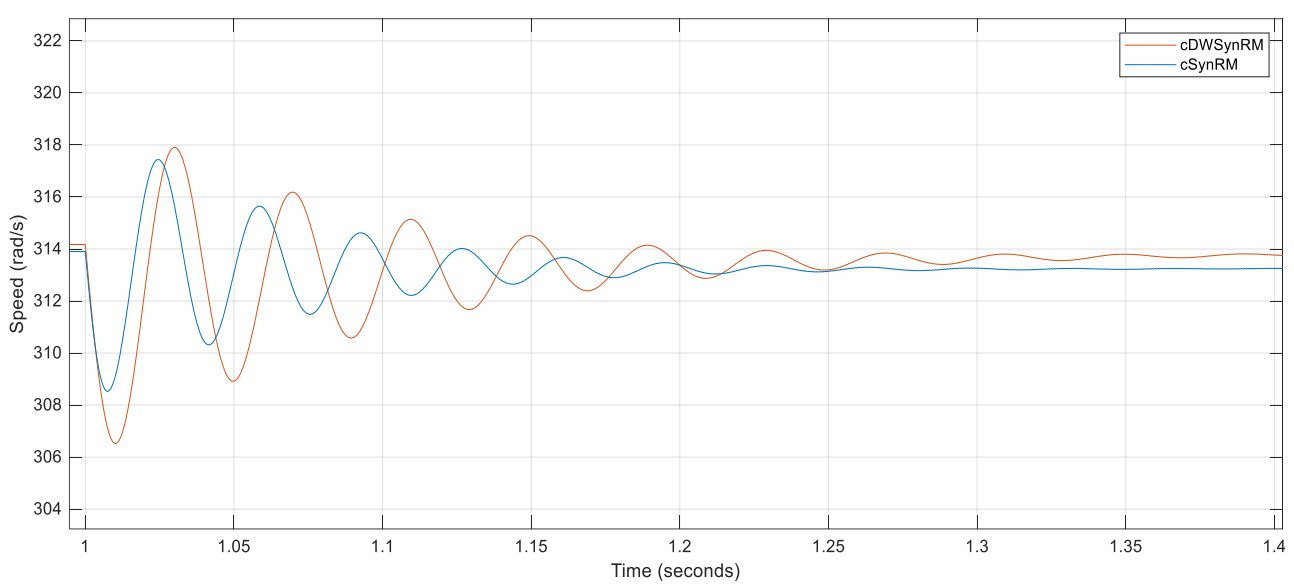

Figure 10. $c D W S y n R M$ and $c$ SynRM speed transient at the introduction of load

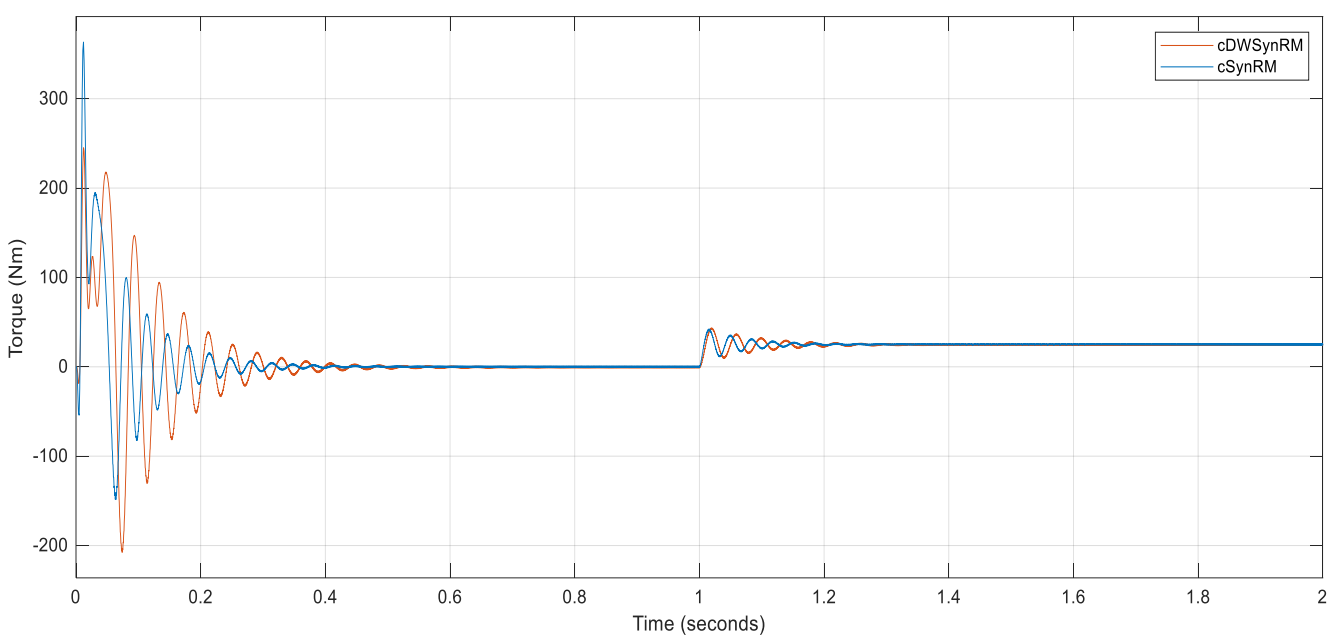

Figure 11. $c D W S y n R M$ and $c S y n R M$ torque against time

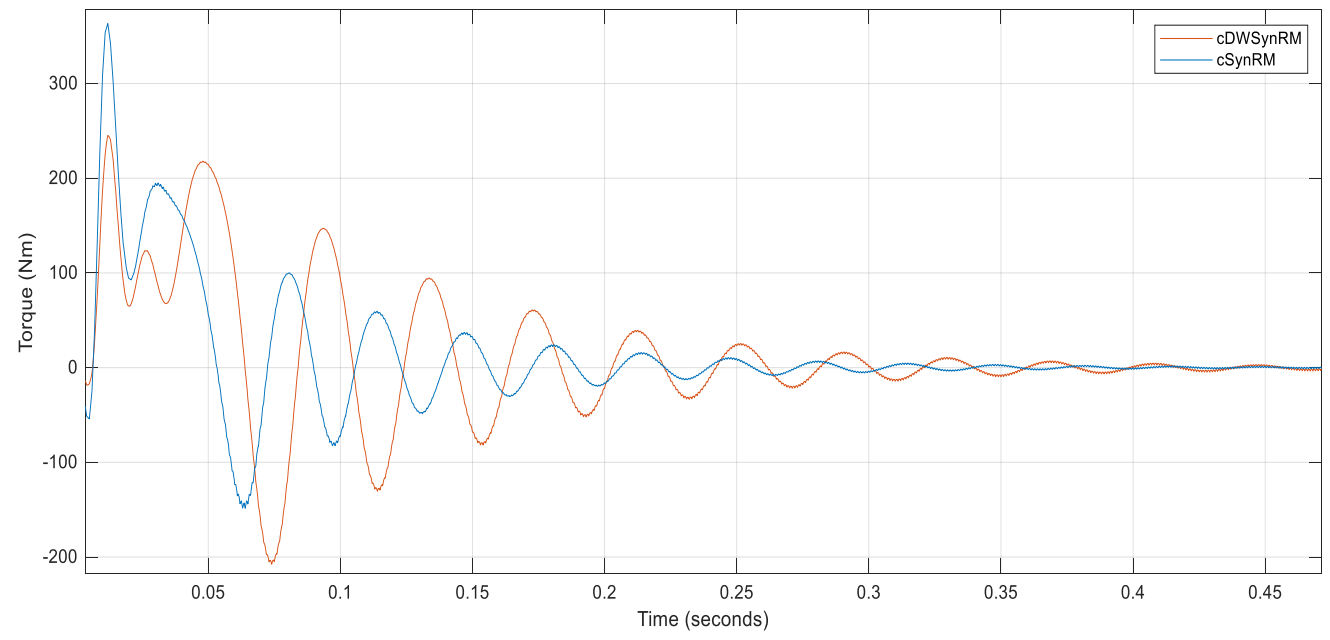

Figure 12. $c D W S y n R M$ and $c S y n R M$ torque transient at start-up 


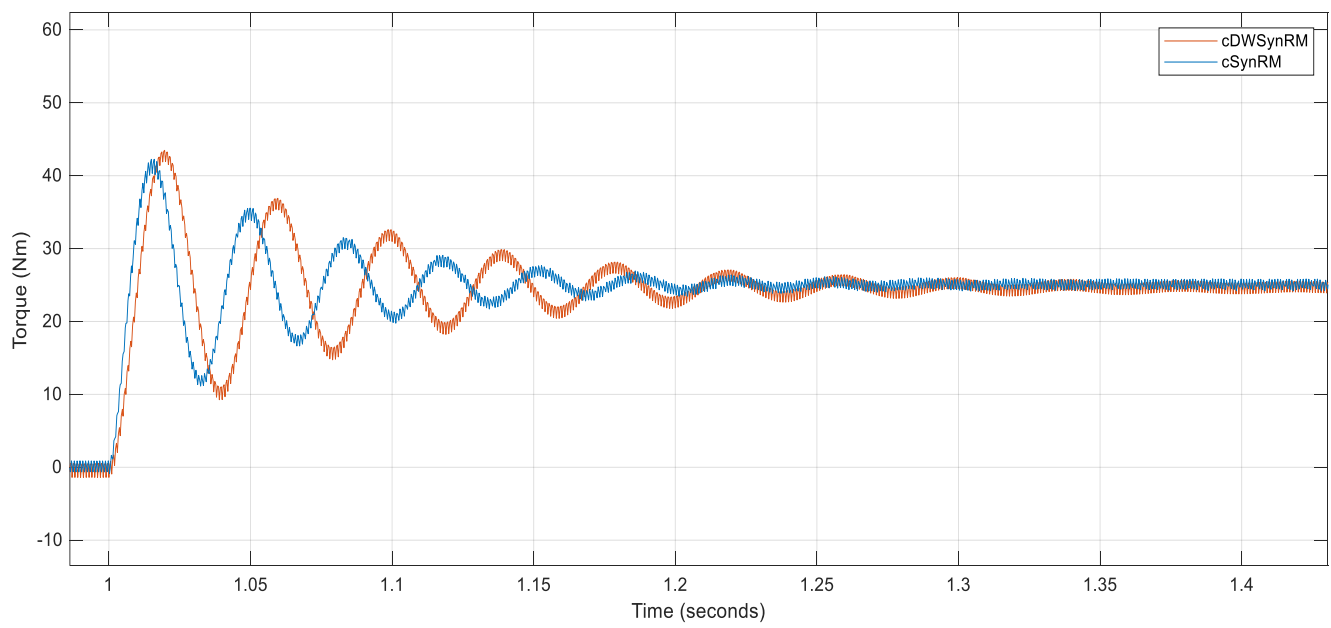

Figure 13. $c D W S y n R M$ and $c$ SynRM torque transient at load introduction

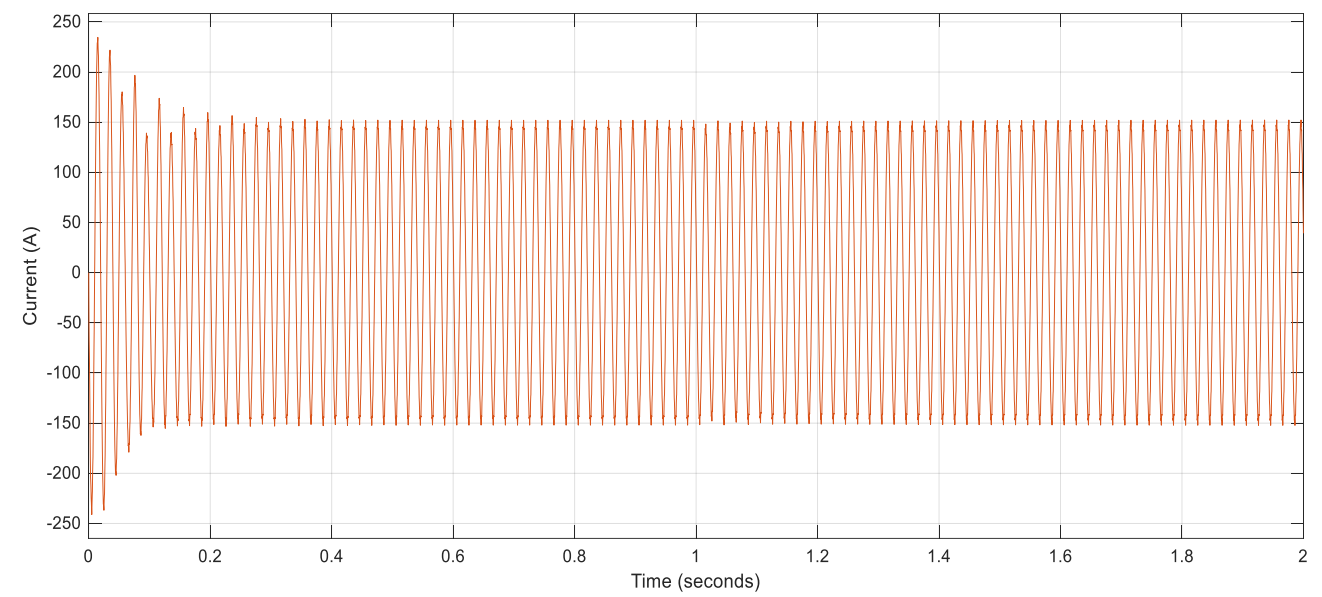

Figure 14. cDWSynRM main winding phase A current against time

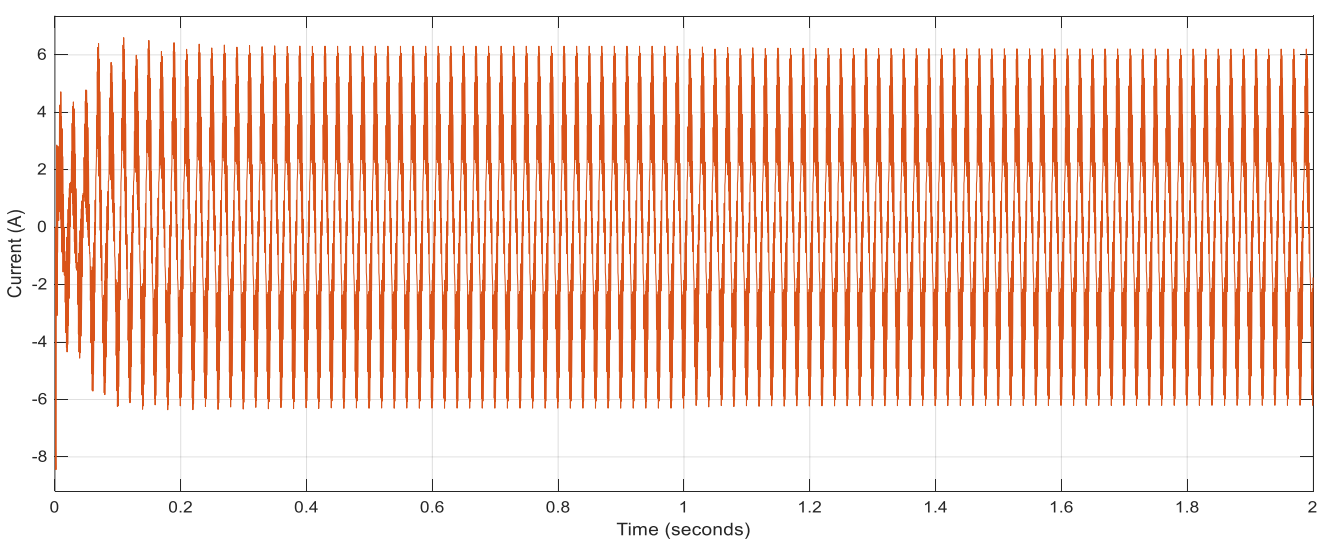

Figure 15. cDWSynRM auxiliary winding phase X current against time 


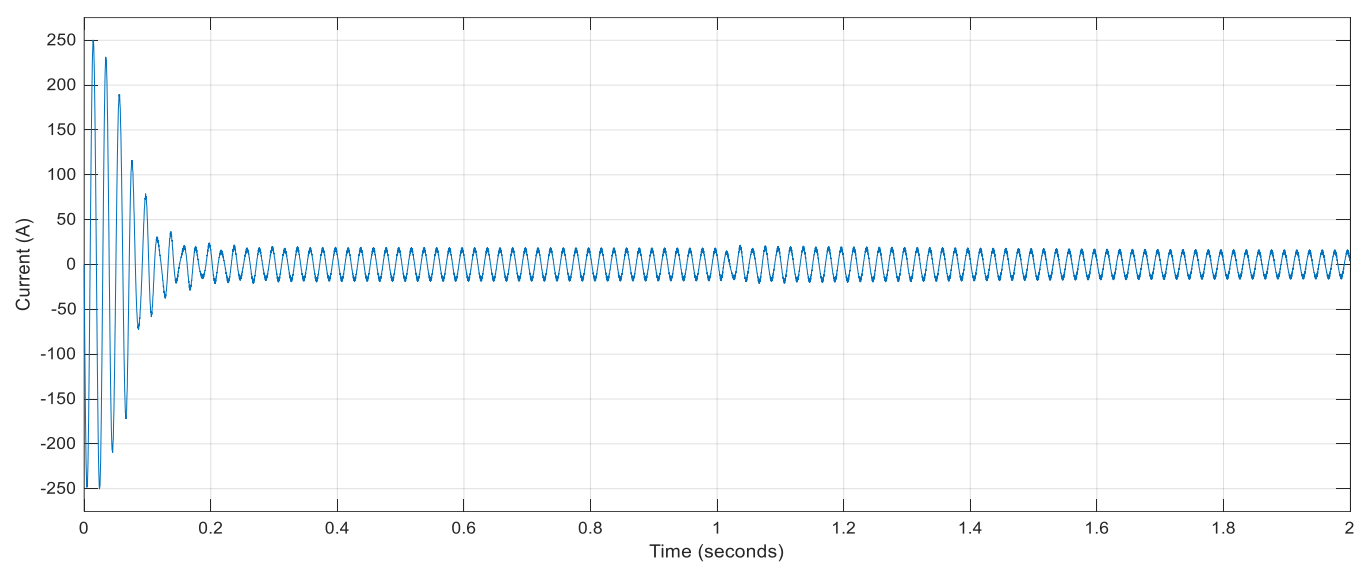

Figure 16. $c$ SynRM phase A current against time

The main stator winding phase A current in Figure 14 will be similar to what will be obtained in phases B and $C$, while the auxiliary stator winding phase $X$ current in Figure 15 will also be similar to that of phases $\mathrm{Y}$ and $\mathrm{Z}$. The phase A stator winding current of the cSynRM was presented in Figure 16.

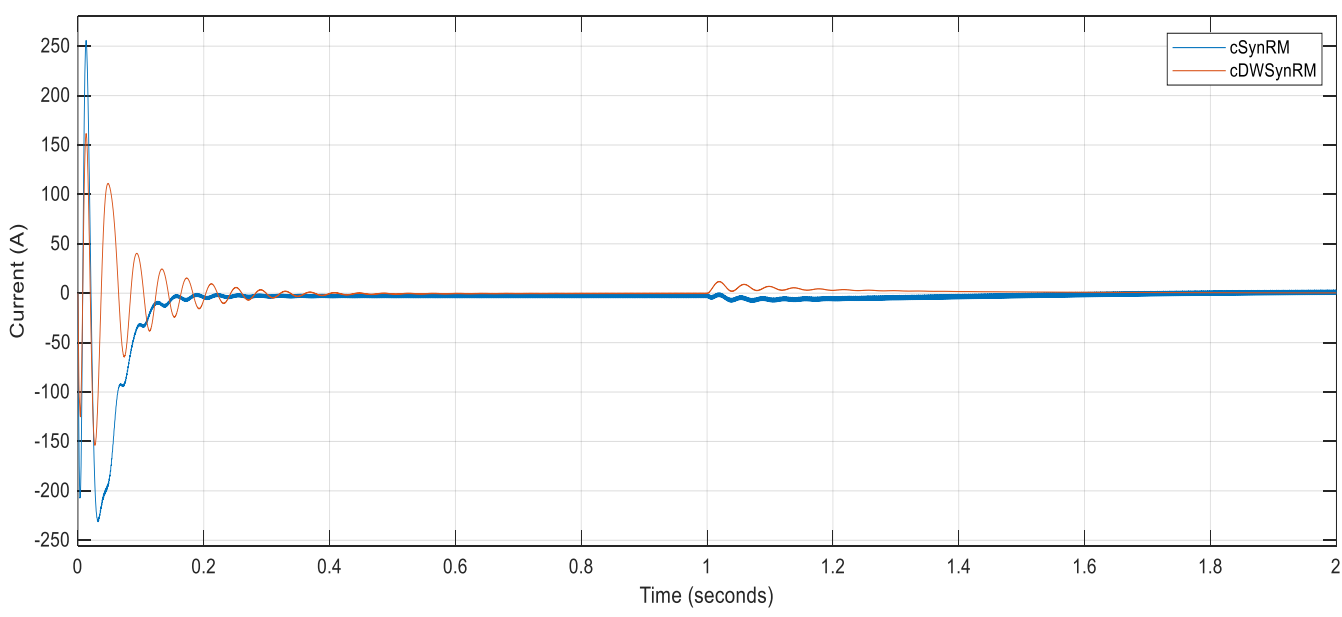

Figure 17. $c D W S y n R M$ and $c$ SynRM rotor d-axis current

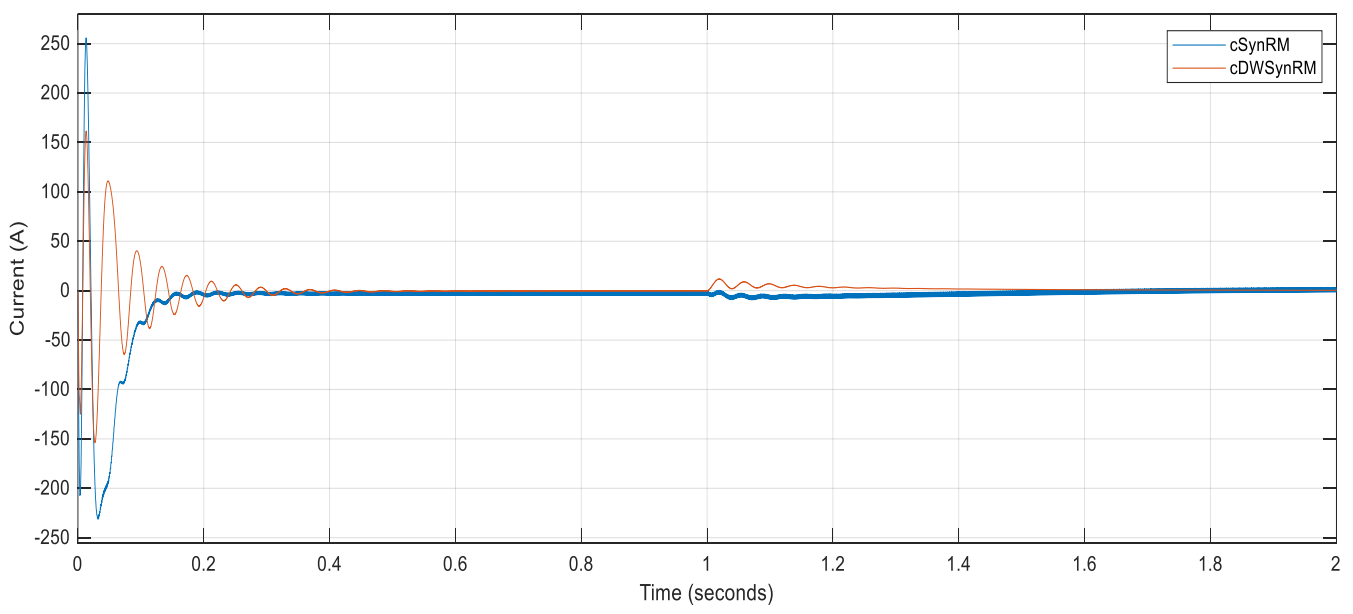

Figure 18. $c D W S y n R M$ and $c$ SynRM rotor q-axis current 
The speed characteristics of the two machine models simulated in direct-phase variables were presented in Figure 8. It was observed from Figure 9, that the cDWSynRM took about 0.6 seconds to attain a synchronous speed of $314.1 \mathrm{rad} / \mathrm{s}$ after having a higher initial speed transient rise of $380.7 \mathrm{rad} / \mathrm{s}$ at start-up. On the other hand, the cSynRM reached a synchronous speed of $314.0 \mathrm{rad} / \mathrm{s}$ at an earlier time of 0.52 seconds, after an initial transient speed rise of $362.3 \mathrm{rad} / \mathrm{s}$.

On the introduction of load torque after 1 second as presented in Figure 10, a transient speed rise of 317.8 $\mathrm{rad} / \mathrm{s}$ was observed for the cDWSynRM which later settled at a synchronous speed of $313.8 \mathrm{rad} / \mathrm{s}$ at 1.35 seconds. The cSynRM at load introduction had a transient speed rise of $317.3 \mathrm{rad} / \mathrm{s}$ and later settled at a synchronous speed of $313.0 \mathrm{rad} / \mathrm{s}$ at about 1.28 seconds.

The torque characteristics of the simulated machine models were presented in Figure 11, it was observed at start-up from Figure 12, that the cDWSynRM torque builds up with a rising value of $245.1 \mathrm{Nm}$, which then falls to $-204.4 \mathrm{Nm}$, before settling at $0 \mathrm{Nm}$ at about 0.5 seconds. The cSynRM had an initial torque build-up of $363.4 \mathrm{Nm}$, which then drops to $-142.9 \mathrm{Nm}$ before settling at $0 \mathrm{Nm}$ at 0.5 seconds. On the introduction of load as seen in Figure 13, the cDWSynRM had a transient rise of $43.3 \mathrm{Nm}$, while the cSynRM had a transient rise of $41.9 \mathrm{Nm}$, they both settled at $25.42 \mathrm{Nm}$ and $25.88 \mathrm{Nm}$ respectively.

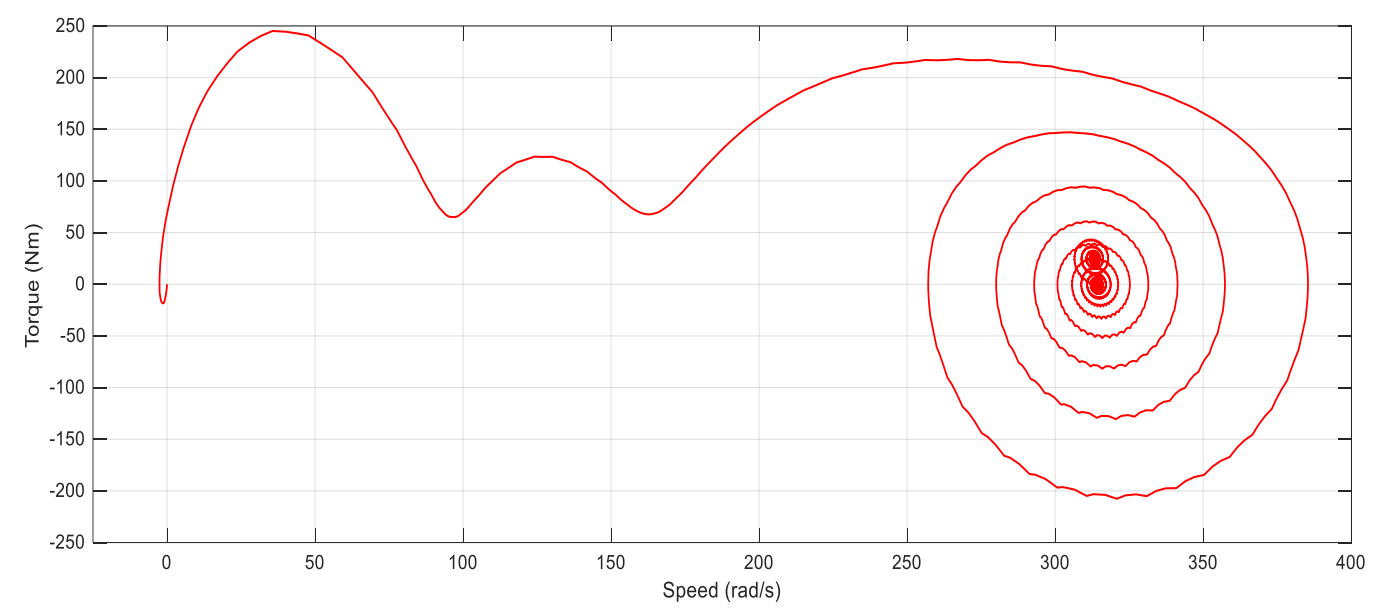

Figure 19. cDWSynRM torque-speed characteristic

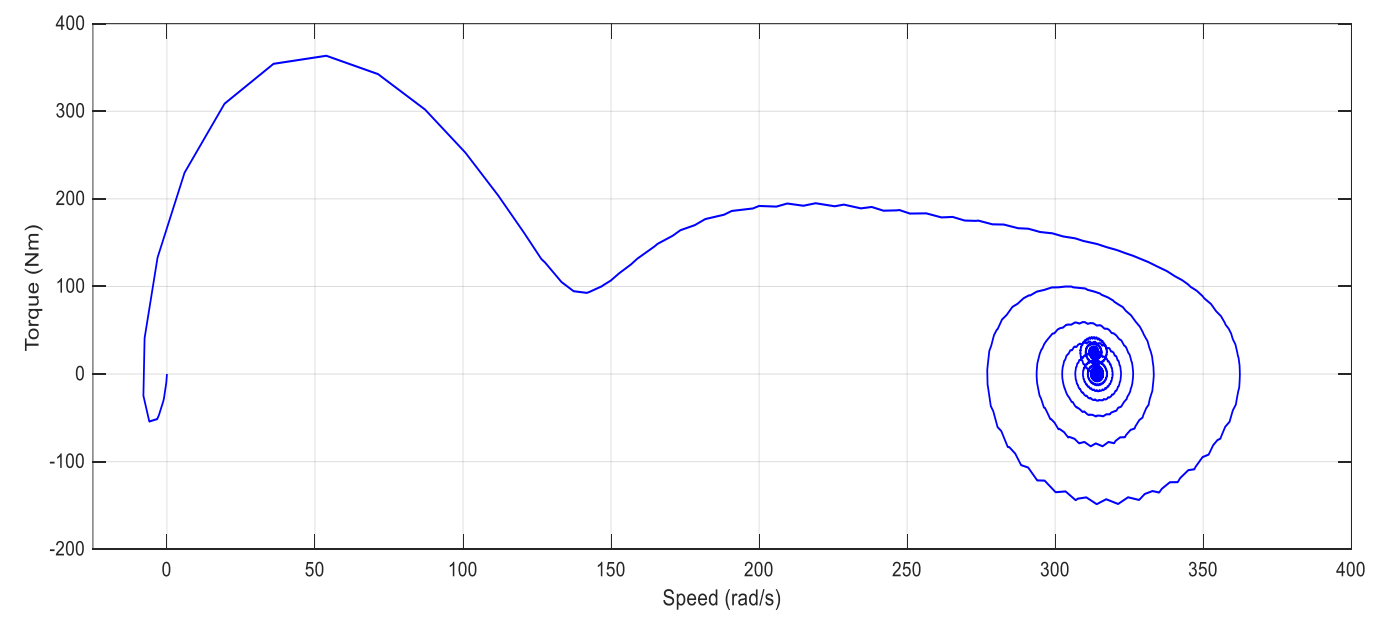

Figure 20. cSynRM torque-speed characteristic

The d-axis and q-axis rotor currents of both machine models were presented in Figures 17 and 18, while their torque-speed characteristics were presented in Figures 19 and 20. The torque-speed characteristics show the relationship between the speed and torque of the machine models throughout the phases of 
operation, from start to full load speed. It was observed from the torque-speed plots that at synchronous speed, an initial settling torque value of $0 \mathrm{Nm}$ was ascertained. On the introduction of load, the torque value moves from $0 \mathrm{Nm}$ to a settling value of $25 \mathrm{Nm}$, as a full load torque occurring at full load speed.

The loading capabilities of the cDWSynRM and cSynRM were determined by the monitoring of their speed characteristics. The motors were placed on Ramp load in MATLAB/Simulink and a load torque of $5 \mathrm{Nm}$ starting value was introduced from 2 seconds as presented in Figure 21. From Figure 22, the cDWSynRM was observed to have lost synchronism at 31.9 seconds, unlike the cSynRM that lost synchronism at an earlier time of 19.8 seconds as presented in Figure 23. Hence, the maximum load torque of the cDWSynRM was $94.8 \mathrm{Nm}$ at 31.9 seconds, while the maximum load torque of the cSynRM was $58.46 \mathrm{Nm}$ at 19.8 seconds. It is worth mentioning that the reason why the cDWSynRM had better torque overload capability when compared to the cSynRM was that the cDWSynRM has higher magnetic flux contributed by the auxiliary winding inductances and also as a result of the mutual coupling inductances that exist between the main and auxiliary windings. It is well known that the magnetic flux is directly proportional to the torque overload capability of a motor, hence the higher the flux the higher the torque overload capability of the motor.

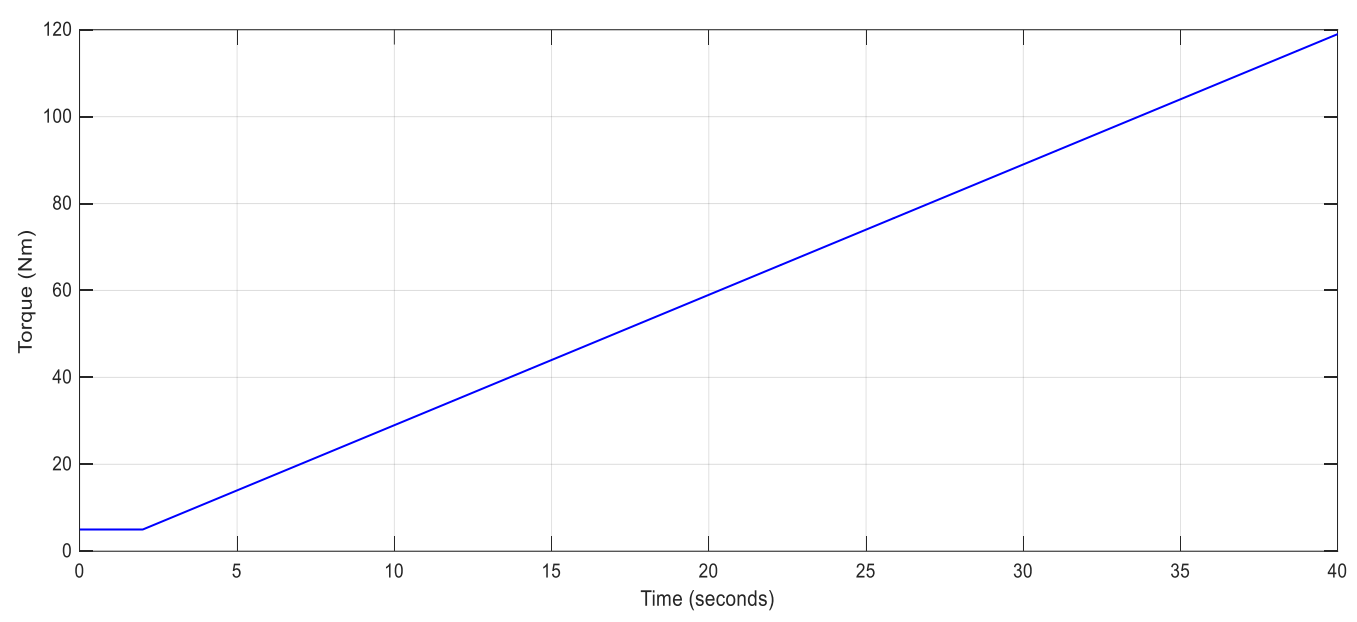

Figure 21. Ramp loading for both cDWSynRM and cSynRM

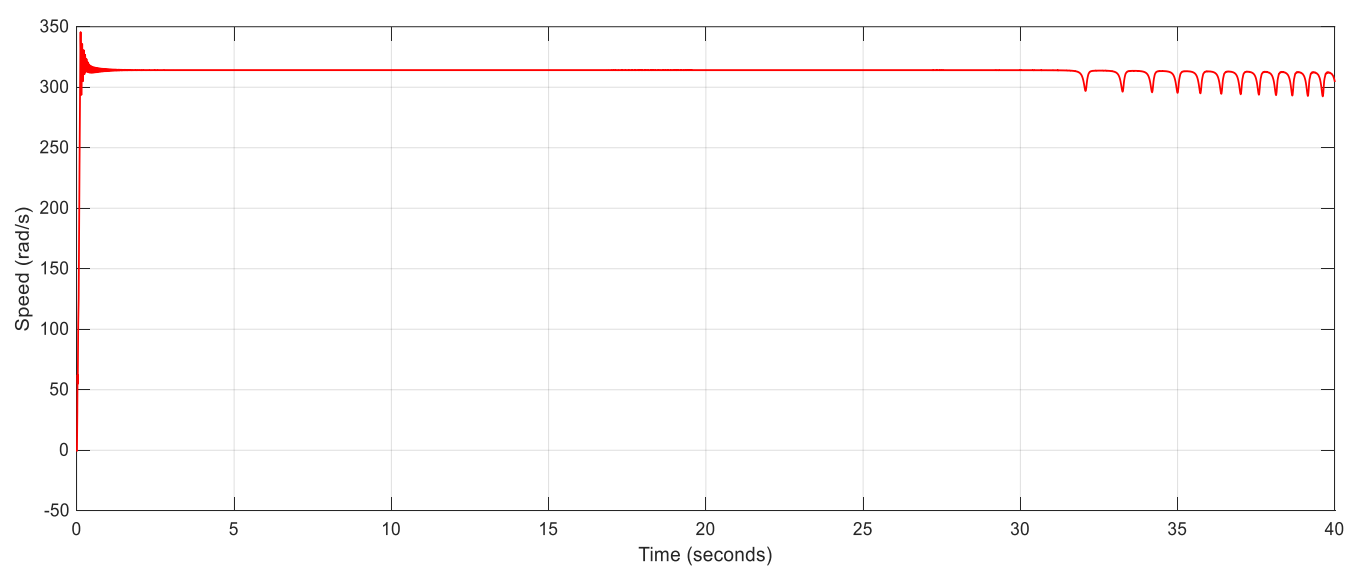

Figure 22. cDWSynRM rotor speed against time under ramp loading 


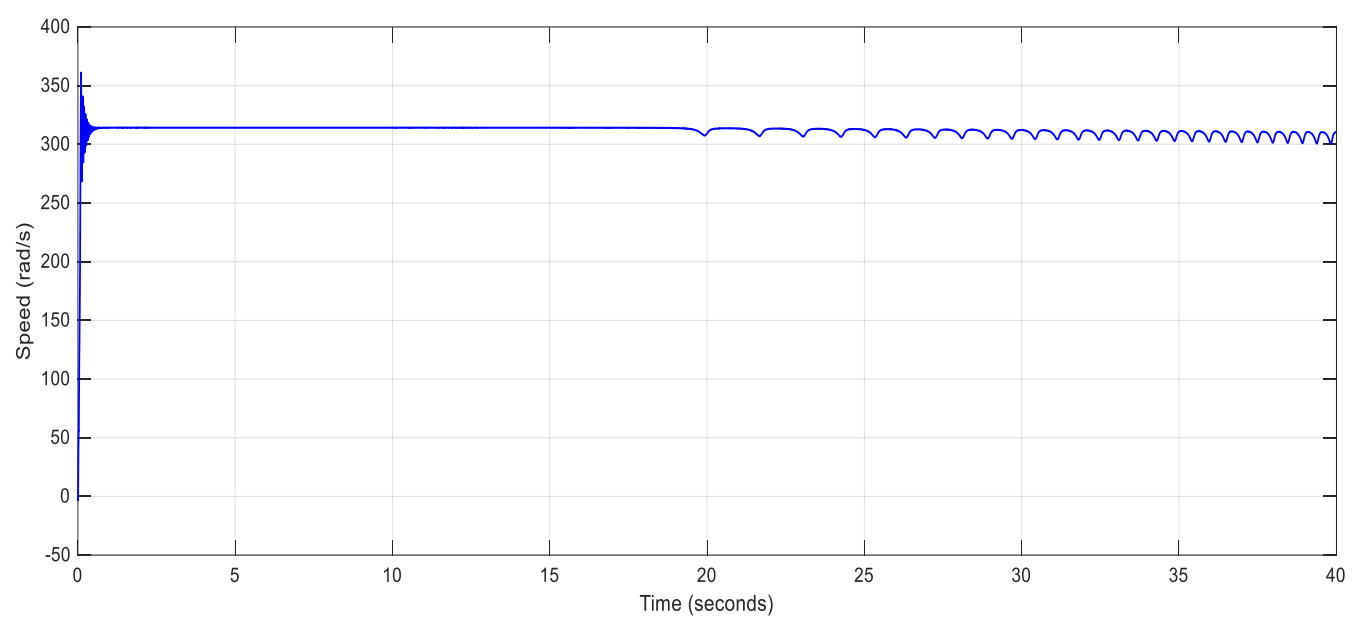

Figure 23. cSynRM rotor speed against time under ramp loading

\section{CONCLUSION}

In this paper, two line-start concentrated winding SynRM models have been successfully modelled and simulated, by utilizing a combination of direct-phase variable model and winding function theory in MATLAB/Simulink. The inductances were initially calculated and the values were used in the dynamic simulation. The performance characteristics such as Speed, Torque, Stator currents, d- and q-axis rotor currents and Torque-Speed of the conventional cSynRM and a proposed cDWSynRM with capacitive assistance were presented. These performance characteristics were observed at start-up and the introduction of $25 \mathrm{Nm}$ load torque after 1 second. Although the cDWSynRM showed slightly higher speed transients, both motors attained synchronism at about the same time.

The results also showed that the cDWSynRM, having half the voltage supply of the cSynRM had better torque and torque overload capability when the motors were placed under Ramp loading. The study has shown that the developed cDWSynRM model is viable and the benefits of concentrated windings and dual stator windings with capacitance injection together resulted in improving the conventional concentrated winding SynRM.

\section{CONFLICTS OF INTEREST}

No conflict of interest was declared by the authors.

\section{REFERENCES}

[1] Obe, E.S., and Binder, A., "Direct-phase-variable model of a synchronous reluctance motor including all slot and winding harmonics", Energy Conversion and Management, 52: 284-291, (2011).

[2] Lipo, T.A., "Synchronous reluctance machine - a viable alternative for AC drives", Electrical Machines and Power System, 19(6): 659-671, (1991).

[3] Vagati, A., "The synchronous reluctance solution: A new alternative in AC drives", 20th Annual Conference of IEEE Industrial Electronics, 1: 1-13, (1994).

[4] Betz R., Lagerquist, R., Jovanovic, M., Miller, T., and Middleton, R., "Control of synchronous reluctance machines", IEEE Transactions on Industry Applications, 29(6): 1110-1122, (1993). 
[5] Boglietti, A., Cavagnino, M., Pastorelli, M., and Vagati, A., "Experimental Comparison of Induction and Synchronous Reluctance Motors Performance", in IEEE Industry Applications Conference, 474479, (2005).

[6] Spargo, C.M., "Synchronous Reluctance Technology-Part I", Durham Research Online, 44(1): 1-5, (2016).

[7] Spargo, C.M., "Synchronous Reluctance Technology Part-II", Durham Research Online, 44(2): 1-6, (2016).

[8] Ojo, O., and Wu, Z., "Synchronous operation of a dual-winding reluctance generator", IEEE Transactions on Energy Conversion, 12(4): 357-362, (1997).

[9] Obe, E.S, "Steady-state performance of a line-start synchronous reluctance motor with capacitive assistance", Electric Power Systems Research, 80(10): 1240-1246, (2010).

[10] Ogunjuyigbe, A.S., Jimoh, A., Nicolae, D.V., and Obe, E., "Analysis of synchronous reluctance machine with magnetically coupled three-phase windings and reactive power compensation", IET Electric Power Applications, 4(4): 291-303, (2010).

[11] Park, J., Bianchini, C., Bellini, A., Davoli, M., and Bianchi, N., "Experiment-based performance analysis for dual three-phase synchronous reluctance motor according to different winding configurations", 2020 International Symposium on Power Electronics, Electrical Drives, Automation and Motion, Conference, (2020).

[12] Umoh, G., Obe, C., Ogbuka, C., Ekpo, G., and Obe, E.S., "Direct-phase variable modelling and analysis of five-phase synchronous reluctance motor for direct-on-line starting", Przeglad Elektrotechniczny, 97(1): 24-29, (2020).

[13] Umoh, G., Ogbuka, C., and Obe, E.S., "Modelling and analysis of five-phase permanent magnet synchronous motor in machine variables", Przeglad Elektrotechniczny, 96(1): 87-92, (2020).

[14] Ogunjuyigbe, A.S., Jimoh, A., and Nicolae, D., "Performance Enhancement of Synchronous Reluctance Machine using Split Winding and Capacitance Injection”, IEEE AFRICON Conference, (2007).

[15] Lehner, B., and Gerling, D., "Design Considerations for Concentrated Winding Synchronous Reluctance Machines”, in IEEE Transportation Electrification Conference, 485-490, (2016).

[16] Tola, J., Obe, E.S., and Anih, L.U., "Modeling and Analysis of Dual Stator Windings Permanent Magnet Synchronous Motor", IEEE 3rd International Conference on Electro-Technology for National Development, 861-871, (2017).

[17] Dehghanzadeh, A. R., and Behjat, V., "Dynamic modeling and experimental validation of a dual-stator PMSG for low speed applications", Gazi University Journal of Science, 28(2): 275-283, (2015).

[18] Cros, J., and Viarouge, P., "Synthesis of High-Performance PM Motors With Concentrated Windings", IEEE Transactions on Energy Conversion, 17(2): 248-253, (2002).

[19] Muñoz, A.R., and Degner, M. W., "Evaluation of Interior PM and Surface PM Synchronous Machines with Distributed and Concentrated Windings", in IEEE International Conference on Industrial Electronics, 1189-1193, (2008). 
[20] Lee, J.J., Kim, W.H., Yu, J.S., Yun, S.Y., and Kim, S.M., "Comparison between concentrated and distributed winding in IPMSM for traction application", International Conference on Electrical Machines and Systems, (2010).

[21] Pouramin, A., Dutta, R., Rahman, M.F., and Xiao, D., "Inductances of a Fractional-Slot ConcentratedWinding Interior PM Synchronous Machine Considering Effects of Saturation and Cross Magnetization", in IEEE Energy Conversion Congress and Exposition Conference, 6075-6081, (2015).

[22] Yue, L., Yulong, P., Yanjun, Y., Yanwen, S., and Feng, C., "Increasing the saliency ratio of fractional slot concentrated winding interior permanent magnet synchronous motors", IET Electric Power Applications, 9(7): 439-448, (2015).

[23] Obe, E.S., "Direct computation of ac machine inductances based on winding function theory", Energy Conversion and Management, 50(3): 539-542, (2009).

[24] Obe, E.S., "Calculation of inductances and torque of an axially laminated synchronous reluctance motor”, IET Electric Power Applications, 4: 783-792, (2010).

[25] Lipo, T.A., Analysis of Synchronous Machines, 2nd ed., Taylor \& Francis Group, LLC, New York, (2012).

[26] Mozaffari, S., "Transient Analysis of Six-Phase Synchronous Machines", Ph.D thesis, University of British Colombia, Canada, 20-26, (1993). 